\title{
Building obesity in Canada: understanding the individual- and neighbourhood-level determinants using a multi-level approach
}

\author{
Theodora Pouliou ${ }^{1}$, Susan J. Elliott ${ }^{2}$, Antonio Paez ${ }^{3}$, K. Bruce Newbold ${ }^{3}$ \\ ${ }^{1}$ Administrative Data Research Centre for Wales, College of Medicine, Swansea University, Swansea, UK; \\ ${ }^{2}$ School of Public Health and Health Systems, Faculty of Applied Health Sciences, University of Waterloo, \\ Waterloo, Canada; ${ }^{3}$ School of Geography and Earth Sciences, McMaster University, Hamilton, Canada
}

\begin{abstract}
The objective of this paper was to identify heterogeneities associated with the relationships between the body mass index (BMI) and individual as well as socio-environmental correlates at the individual-and area-levels. The data sources used were: (i) the 2003 Canadian Community Health Survey; (ii) the 2001 Canadian Census; and (iii) the Enhanced Points of Interest (EPOI) database from the Desktop Mapping Technologies Inc. Participants were adults ( $\geq 20$ years; $n=12,836$; based on a survey weight scheme $\mathrm{N}_{\text {weighted }}=5,418,218$ ) from Toronto and Vancouver census metropolitan areas with no missing BMI records. In addition to conventional $1 \mathrm{~km}$-buffers, we constructed activity-space-buffers to better assess the walkability and potentially increased BMI of individuals. Multi-level analysis was then applied to estimate the relative effects of both individual- and area-level risk-factors for increased BMI. The findings demonstrate a negative association between BMI and energy expenditure, mixed land uses, residential density and average value of dwellings, while a positive association was found with low educational attainment. Relationships were independent of individual characteristics such as age and ethnicity. Although the majority of the variation in these outcomes was found to be due to individual-level differences, this study did show significant differences at the area-level as well. The activity-space-buffers presented a vast improvement compared to the conventional $1 \mathrm{~km}$-buffers. The results presented support the rationale that targeting high-risk individuals will only address a portion of the increasing BMI problem; it is essential to also address the characteristics of places that compel individuals to make unhealthy choices.
\end{abstract}

Keywords: body mass index, obesity, built environment, walkability index, geographical information system, Canada.

\section{Introduction}

Overweight/obesity are now recognised as not only a major public health problem but as a global epidemic (WHO, 2013). In 2008, 35\% of the adult population (aged $\geq 20$ years) were overweight and $11 \%$ were obese (WHO, 2013). Within the Canadian context, the 2008 Canadian Community Health Survey (CCHS) identified that approximately $25 \%$ of adults were obese and when combined with overweight, the prevalence was $62 \%$ based on measured height and weight data (Public Health Agency of Canada \& Canadian Institute for Health Information, 2011).

Overweight/obesity have been shown to be associated to various health problems, such as type II diabetes, cardiovascular diseases and psychosocial issues, such as depression (Raine, 2004). Further, they are associated with an increased prevalence of primary-care visits,

Corresponding author:

Theodora Pouliou

School of Social and Community Medicine

University of Bristol, 39 Whatley Road, BS82PS, Bristol, UK

Tel. +4401179287239

E-mail: dora.pouliou@gmail.com exacerbating the load on an already overburdened health-care system (Janssen, 2013). Yet, in spite of the magnitude of the problem, there is still much to be learned about the factors contributing to the obesity epidemic. Research on the determinants of overweight/obesity has primarily focused on exploring and identifying individual-level risk factors such as age, gender, diet and physical (in)activity (Raine, 2004; Tjepkema, 2005; Crosnoe, 2007; Herrera and Lindgren, 2010). While individual factors are without doubt important, they do not fully explain the prevalence of obesity by themselves (Robert and Reither, 2004; Harrington and Elliott, 2009; Poortinga et al., 2011). For this reason, the scientific community has shown a growing interest on the aspects of the environment that could serve as potential determinants of increasing body mass index (BMI). However, most studies to date have focused on the built environment of the neighbourhood; they show that individuals are more likely to have lower BMI if their neighbourhood has facilities such as walking/cycling paths, street connectivity and land use (Frank et al., 2004, 2008, 2009; Ross et al., 2007; Zick et al., 2009). Few have explored the association between increased BMI and characteristics of the socio-economic environment or a 
combination of both (Frank et al., 2008; Navalpotro et al., 2012).

In addition, as noted by recent reviews (Feng et al., 2010; Ding and Gebel, 2012), there are still methodological challenges that influence the strength or even consistency of the potential association between increased BMI and the environment. Most research to date focuses on either perceived or objective measures of the physical and/or socio-economic environment (Ding and Gebel, 2012). Furthermore, the definition of the spatial unit that would best represent a respondent's local environment remains a challenge. A number of studies have used either pre-defined spatial units such as census tracts (Boer et al., 2007; Leslie et al., 2007; Ross et al., 2007) or spatial information (e.g. addresses, postal codes) to establish a circular buffer around respondents' geocoded location at a given radius (Frank et al., 2004). A limitation of this approach is that pre-defined areas may not correspond to areas that individuals actually use (Páez et al., 2010; Morency et al., 2011). More recently, studies have created buffers based on mobility patterns and have been mainly applied in other research areas, e.g. transportation (Kwan, 1999; Chaix et al., 2009; Morency et al., 2011). New research is required on the rigorous validation of these methods.

While the volume of literature exploring the determinants of increased BMI is expanding, the field offers important opportunities for further study. Current research findings suggest that the social context of the determinants of overweight/obesity are not well explored and require further investigation. In addition, existing studies have assessed the extent to which circular or activity-space buffers influence walking patterns and the potential association between weight status and the built environment. Therefore, the main objective of this research is to examine the individual and environmental (based on both objective and reported measures of the physical and socio-economic environments) determinants of increased BMI in urban Canada. The analysis grid for environments linked to obesity (ANGELO) framework was employed to effectively categorise elements of the local environment (the arealevel of the analysis) that could potentially be driving the obesity epidemic in Canada (Swinburn et al., 1999). We chose Canada's two largest metropolitan areas (Toronto and Vancouver) for two reasons. First, approximately $20 \%$ of all Canadians live in these two metropolitan areas. Second, both census metropolitan areas (CMAs) are characterised by various neighbourhood designs ranging from high to low on a continuum of walkability and residential density. Thus,
Toronto and Vancouver CMAs provide a useful case study for the individual and socio-environmental determinants of overweight/obesity in Canada.

\section{Material and methods}

\section{Data}

Three data sources were employed for this study namely:

(i) the 2003 CCHS, Cycle 2.1, master file;

(ii) the 2001 Canadian Census of Population; and

(iii) the CanMap-RouteLogistics (CMRL) spatial information database on land uses and the Enhanced Points of Interest (EPOI) file from the Desktop Mapping Technologies Inc. (DMTI; http://www.dmtispatial.com/).

These data sources were matched based on postal code residential information available in the master files of the CCHS.

The CCHS provides cross-sectional health and social indicator information on a large representative sample of Canadians and is intended to provide reliable estimates of health outcomes and health determinants at sub-provincial scales. The target population of the CCHS is individuals $\geq 12$ years of age living in private dwellings, excluding those living on Indian Reserves or Crown lands, the institutionalised population, full-time members of the Canadian Armed Forces and residents of certain remote regions. Using a multistage stratified cluster design approach, a total of 134,072 individuals participated in the CCHS 2.1, with a response rate of $80.7 \%$. A detailed description of the CCHS design and questionnaire is available at Statistics Canada (2005a). Using the CCHS master file and the Statistics Canada's postal code conversion file allowed access to a sub-national disaggregation of the data and linkage with the DMTI spatial database and the 2001 Canadian Census of Population. Individuallevel data were linked to the 2001 Canadian census profiles using the postal codes recorded for each respondent in the CCHS at the dissemination area (DA) level. We chose the DA as the area-level of analysis, at it is the smallest standard geographic area for which all census data are disseminated.

\section{Body mass index}

BMI is a simple index calculated as the weight in kilograms divided by the square of the height in metres $\left(\mathrm{kg} / \mathrm{m}^{2}\right)$ that is commonly used to classify adults with respect to weight. We used BMI as a continuous vari- 
able for the following reasons: (i) dichotomizing BMI into overweight/obese versus optimal-weight/underweight would not have allowed for an unrestricted assessment of BMI; and (ii) any categorisation may have resulted in dealing with marginal cases (e.g. does a $\mathrm{BMI}=29.9$ indicate a optimal weight or an overweight individual?). BMI was calculated based on selfreported height and weight data. Individuals with missing BMI records due to invalid data were excluded from the analysis. All data were weighted using the combined weight provided by Statistics Canada as part of the public use micro-data file (Statistics Canada, 2005b). In particular, in order for the estimates produced from the survey data to be representative of the populations covered and not the just sample itself, we incorporated survey weights into the analysis. These weights took into account the sampling frame, design and estimation/implementation. Results based on weighted analysis are presented as $\mathrm{N}$-weighted. The final sample included in the analysis was 12,836 participants $(\mathrm{N}$-weighted $=5,418,218) \geq 20$ years of age residing in Toronto and Vancouver CMAs.

\section{Individual-level explanatory variables}

Selection of variables was based on existing literature and specifically, the broader determinants of health according to the population health perspective (Evans et al., 1994; Raine, 2004). The variables included may be divided into the following categories: (i) lifestyle; (ii) socio-economic status; and (iii) variables relating to the built and social environments. Lifestyle variables included physical activity and fruit/vegetable consumption, while income adequacy (based on income and household size), employment status, home ownership and education level comprised the socio-economic variables. Characteristics of the social environment of the individuals were also acquired from the CCHS data and included information on whether the individual was a member of a voluntary organisation and their sense of belonging to the local community.

Seven built-environment variables were constructed based on the DMTI database: land use mix (LUM), street network connectivity, residential density and density of fast-food restaurants, convenience stores, grocery stores and recreational centres. Built environment data were linked to individualised buffers to measure the built environment near the participant's residence. Brief operational definitions for each appear below.

LUM was operationalised using the method provided by Frank and Engelke (2001). In this study, data for five land use types were available (i.e. residential, commercial, industrial, institutional and open space). In general, LUM values vary on a continuous scale between 0 and 1 , with the latter indicating an even distribution of all land use categories (heterogeneity) and zero implying a single type of land use (homogeneity). Street network connectivity was defined as the number of street intersections divided by area in $\mathrm{km}^{2}$. Residential density denotes the number of occupied households per residential land use in $\mathrm{km}^{2}$. Three variables were considered for characterising the density of various opportunities; namely the number of fast-food restaurants, convenience stores, grocery stores and recreational centres. Data were divided by area in square $\mathrm{km}^{2}$ to obtain comparable units.

\section{Confounding factors}

We controlled for chronic conditions (i.e. blood pressure, diabetes, arthritis/rheumatism and anxiety/mood disorder) and demographic characteristics (i.e. age, gender and ethnicity) that could influence the association between BMI and its determinants. Categorical representations of these explanatory variables were included within the models based upon a priori expectations, with value " 1 " used as the reference category, typically representative or linked to poorer states of health (i.e. regular smokers, heavy drinkers, suffering from a chronic disease).

\section{Dissemination area-level explanatory variables}

According to the definitions advocated by Swinburn et al. (1999), neighbourhood is defined as a microenvironmental setting, rather than a macro-environmental sector; therefore, we only adapted the microenvironmental setting of the ANGELO grid (Swinburn et al., 1999) at the DA-level. Variables from the census were grouped within the environment types specified by the ANGELO framework, which divides the environment into two dimensions: the size (home and dissemination area) and the type of the environment (e.g. physical, socio-cultural, economic and political). In particular, Table 1 presents all the area-level variables considered based on the literature. For the physical environment, older homes (houses built prior to 1946) were used as proxies for neighbourhood characteristics (Berrigan and Troiano, 2002), and homes in need of major versus minor repairs were selected as indicators of neighbourhood aesthetics. For socio-cultural variables, the proportion of home owners versus those in rental homes was calculated as a proxy for neigh- 
bourhood social cohesion. It was expected that home owners would be more inclined to invest in their direct surroundings and be more attached to their neighbourhood than those in a more transient, rental-based residency situation (Brown et al., 2003). As part of the preliminary analysis, we also tested the association between the proportion of households with single parent families and BMI and found no significant association with the outcome of interest. Finally, proportion of the neighbourhood with at least high-school education, was included as a socio-cultural environmental correlate. Since education can be used as a proxy for health literacy (Crosnoe, 2007), it may be more likely to represent a neighbourhood's attitudes and beliefs about obesity, rather than representing measures of the costs related to obesity, as with economic environmental factors (Swinburn et al., 1999). For the latter, we included variables such as the average and median household income, average dwelling value, proportion of households below the low-income cut-off (Statistics Canada, 2008), and the unemployment rate (LahtiKoski et al., 2000). No measures of the political environment were available in the census profiles and therefore could not be taken into consideration in the analysis.

\section{Statistical analysis}

Analyses were performed using SAS 9.2 (SAS Institute Inc., 2008). A number of outliers were excluded from the analysis as we deemed their BMI values to be inaccurate (i.e. cases were excluded if the reported BMI was more than $100 \mathrm{~kg} / \mathrm{m}^{2}$ and could not be justified by all other characteristics of the individual).

Spatial data analysis and geographical information system (GIS) techniques were employed to assess the contribution of the built environment. The process involved three steps: (i) geocoding participants' residential addresses; (ii) creating buffers (i.e. bounded areas of a specific dimension, around each residence location in which built environment features are subsequently quantified); and (iii) linking built environment data (e.g. land uses) to geocoded participants' buffers to measure the built environment near the participant's residence (e.g. land use mix). ArcView version 3.3 (ESRI, 2002) was used to geocode participant addresses and create buffers around the participants' residences.

Conventional and activity-space-buffers were created for the purposes of this study. Conventional buffers had a radius of $1 \mathrm{~km}$ around the centroid of each respondent's postal code in the CCHS sample. The radius of the activity-space-buffer was estimated using the model developed by Morency et al. (2011), which was developed for three major Canadian urban centres; Hamilton, Toronto and Montreal and was therefore applied only for Toronto. Buffers were created around each respondent's postal code using individualised travel-distance that resulted from the model as radius (range of values $=1.2-6.5 \mathrm{~km}$ ). For comparison purposes, buffers equal to the median travel-distance $(3.94 \mathrm{~km})$ were also constructed for both Toronto and Vancouver.

All variables found to be statistically significant at the 0.05 level in bivariate models were included in multivariate models. A type II analysis of variance test followed to test the significance of each variable to the overall fit of the model. Multicollinearity was assessed using the variance inflation factor for each estimator (for both individual- and area-levels of analysis). All variables found to be statistically significant after this stage were included as the individual-level basis for the multilevel analyses. To test whether associations were similar for both men and women, we also modelled the interaction of all independent variables with gender. Further, to address whether some individual-level variables, such as physical activity acted as mediators in the pathway relating neighbourhood characteristics to BMI, we also tested for potential interactions between energy expenditure as well as fruit and veg-

Table 1. Classification variables based on the ANGELO framework.

\begin{tabular}{|c|c|c|c|c|}
\hline $\begin{array}{l}\text { Type of setting } \\
\text { investigated }\end{array}$ & $\begin{array}{l}\text { Physical } \\
\text { environment }\end{array}$ & $\begin{array}{l}\text { Social-cultural } \\
\text { environment }\end{array}$ & $\begin{array}{l}\text { Economic } \\
\text { environment }\end{array}$ & $\begin{array}{l}\text { Political } \\
\text { environment }\end{array}$ \\
\hline Home & Pre-1946 homes (\%) & Rented home (\%) & $\begin{array}{l}\text { Average household income } \\
\text { Median household income }\end{array}$ & \\
\hline \multirow[t]{2}{*}{ Dissemination area } & Homes needing major repair (\%) & High-school education ( $\%$ ) & $\begin{array}{l}\text { Average dwelling value } \\
\text { Low-income families ( } \% \text { ) }\end{array}$ & Not available \\
\hline & Homes needing minor repair $(\%)$ & & Unemployment rate (\%) & \\
\hline
\end{tabular}


etable consumption and each of the neighbourhood variables. Results were presented only when the interaction term was significant at the 0.05 level.

The multi-level models used to assess the potential influence of area-level variables were computed using MLwiN v.2.01 (Rasbash et al., 2009). Random intercept and fixed slopes models are presented. We also fitted a random slopes model; however, no variables had significant slope variance. An intra-class correlation coefficient (ICC) was estimated to determine the proportion of the total variability that is accounted for by differences among areas (Snijders and Bosker, 1999). Generally, a decline in the ICC indicated that the differences between areas had been reduced by the inclusion of explanatory variables.

\section{Results}

The coefficients may be interpreted as the absolute change in the outcome variable associated with a oneunit increase in the independent variable for continuous variables (e.g. energy expenditure). For categorical variables, these coefficients can be interpreted as the difference between mean BMI and levels of that categorical variable (e.g. not having completed a high school education) and the reference group (e.g. completed high school education), while controlling for all other variables in the model. Tables 2 and 3 also reference confounding variables (e.g. age, gender, high blood pressure, diabetes and arthritis/rheumatism) that have been used in order to analyse the relationship between BMI and its determinants independent from their impact.

Energy expenditure and smoking were negatively associated with BMI. Fruit and vegetable consumption was also tested but not presented here, as they were not significant at the 0.05 level (Tables 2 and 3).

High school education was found to be positively associated with BMI, indicating that individuals with higher secondary education had increased BMI compared to those with equal or less than secondary educational attainment. This relationship, although marginally significant in models 1 and 2 for Toronto (Table 2) and model 2 for Vancouver (Table 3) emerged as a much stronger indicator than any other measure of socio-economic status (e.g. average family income or income adequacy).

With regard to the built environment, three variables were included in the models; LUM, residential density and street connectivity. However, measures of the built environment could be correlated. To avoid this issue, the variance inflation factor between BMI and the built environment variables was estimated. The values of the variance inflation factor were close to one, indicating that multicollinearity between the built environment variables was not an issue (Table 4).

Individuals living in areas with mixed land uses have lower BMI for both Toronto and Vancouver than those living in areas with a single or few land use types. Residential density was also negatively associated with BMI for Vancouver, but not for Toronto. In addition, street connectivity was not found to be significantly associated with BMI for both Toronto and Vancouver. The relationship between BMI and LUM was significant in models 1 and 2 in Toronto but not in model 3. None of the potential mediators (physical activity and diet) in the pathway relating neighbourhood characteristics to BMI were statistically significant. Statistically significant gender differences appeared in terms of the psychological and socio-economic characteristics of the individuals. Females with low levels of education (high school or less) had higher BMI's compared to those with higher levels of education. However, the association was marginally significant in model 3 for Toronto and models 2 and 3 for Vancouver and therefore the results need to be interpreted with caution.

The ICC's indicated that considerable proportions of the variation occurred at the neighbourhood-level, with values ranging between $1.2 \%$ and $3.1 \%$ for Toronto and $4.1 \%$ and $4.5 \%$ for Vancouver. In particular, for Toronto, findings revealed that individuals living in areas with low average dwelling value had higher BMI's than those living in areas with high average dwelling value.

\section{Discussion}

The findings reported here underscore the evidence for an adverse association between BMI and energy expenditure, LUM, residential density, average value of dwellings and a positive association with low educational attainment, even after controlling for age, gender, chronic diseases and ethnicity. The major variations in these outcomes was found to be due to individual-level differences rather than area-level differences. However, this study did show significant differences at the area-level of analysis, supporting existing research suggesting that individual-level factors alone cannot explain variation in obesity rates across space (Ewing et al., 2003; Mobley et al., 2004; Frank et al., 2006, 2008, 2009). These results further explicate the importance of the ANGELO framework in order to better understand the nature of the relationships 
Table 2. Individual and area-level correlates of BMI based on multi-level modeling analysis - Toronto, CMA.

\begin{tabular}{|c|c|c|c|}
\hline Variable & $\begin{array}{l}\text { Model } 1 \text { (95\% CI) } \\
\text { (individualised travel-distance) }\end{array}$ & $\begin{array}{l}\text { Model } 2 \text { (95\% CI) } \\
\text { (median distance-traveled) }\end{array}$ & $\begin{array}{l}\text { Model } 3(95 \% \mathrm{CI}) \\
(1 \mathrm{~km} \text { buffer })\end{array}$ \\
\hline Intercept & $13.47(10.64,16.30) * * *$ & $19.51(17.09,21.93) * * *$ & $16.88(16.06,17.70) * * *$ \\
\hline \multicolumn{4}{|l|}{ Age (years) } \\
\hline$<20$ & $-2.20(-3.12,-1.28) * * *$ & $-2.22(-3.14,-1.30) * * *$ & $-2.61(-3.11-2.11) * * *$ \\
\hline $20-35$ & $-1.04(-1.48,-0.60) * * *$ & $-1.07(-1.51,-0.63) * * *$ & $-0.61(-0.04,0.56)$ \\
\hline 36-50 (reference) & - & - & - \\
\hline $51-64$ & $0.30(-0.20,0.80)$ & $0.27(-0.23,0.77)$ & $0.26(0.21,0.64) * * *$ \\
\hline$\geq 65$ years of age & $-1.18(-0.65,-0.53) * *$ & $-1.16(-0.62,-0.54) *$ & $-1.23(-1.62,-0.84) * * *$ \\
\hline Female (reference) & - & - & - \\
\hline Male & $1.08(0.43,1.73) * *$ & $0.93(0.28,1.55) * *$ & $1.19(0.74,1.64) * * *$ \\
\hline Arthritis - rheumatism & $0.96(0.50,1,42) * * *$ & $0.94(0.48,1.41) * * *$ & $0.83(0.53,1.12) * * *$ \\
\hline High blood pressure & $2.00(1.52,2.48) * * *$ & $1.97(1.49,2.45) * * *$ & $2.04(1.74,2.34) * * *$ \\
\hline Diabetes & $2.10(1.35,2.85) * * *$ & $2.07(1.34,2.84) * * *$ & $1.92(1.44,2.40) * * *$ \\
\hline Anxiety - mood disorder & $0.58(-0.07,1.23)$ & $0.62(-0.03,1.27)$ & $1.02(0.54,1.51) * * *$ \\
\hline Energy expenditure & $-0.13(-0.22,-0.05) * * *$ & $-0.13(-0.22,-0.05) * * *$ & $-0.14(-0.19,-0.09) * * *$ \\
\hline Regular smoker & $-0.49(-0.90,-0.08) * * *$ & $-0.52(-0.90,-0.11) * * *$ & $-0.46(-0.72,-0.21) * * *$ \\
\hline Race - white & $1.45(0.91,1.99) * * *$ & $1.49(0.94,2.03) * * *$ & $1.34(0.99,1.69) * * *$ \\
\hline Race - Asian (reference) & - & - & - \\
\hline Race - other & $1.67(0.79,2.55) * * *$ & $1.68(0.80,2.48) * * *$ & $1.41(0.80,2.01) * * *$ \\
\hline Less than secondary & $0.05(0.02,0.08) *$ & $0.02(0.02,0.02) *$ & $0.99(0.58,1.39) * * *$ \\
\hline Secondary & $0.03(0.00,0.06) *$ & $0.01(0.002,0.02) *$ & $0.54(0.19,0.89) * *$ \\
\hline More than secondary (reference) & - & - & - \\
\hline Land use mix & $-5.81(-8.96,-2.65) * * *$ & $-6.12(-9.12,-3.12) * * *$ & $-0.22(-0.30,0.04)$ \\
\hline Street connectivity & $-0.002(-0.004,0.003)$ & $-0.04(-0.01,0.04)$ & $-0.001(0.00,0.00)$ \\
\hline Residential density & $-0.04(-0.11,0.16)$ & $-0.001(-0.10,0.02)$ & $-0.06(-0.11,0.01)$ \\
\hline Anxiety - mood disorder * males & $0.55(0.30,0.80) *$ & $0.60(0.27,0.93) *$ & $-0.99(-1.82,-0.16) * *$ \\
\hline Race - white *males & $0.90(0.15,1.65) * *$ & $0.88(0.13,1.63) * *$ & $0.80(0.31,1.30) * *$ \\
\hline Race - Asian * males (reference) & - & - & - \\
\hline Race - other * males & $0.08(-1.19,1.35)$ & $0.11(-1.17,1.38)$ & $0.26(-1.41,-0.26)$ \\
\hline Less than secondary * males & $-0.03(-0.72,0.66)$ & $-0.03(-0.69,0.63)$ & $-0.84(-2.85,-0.41) *$ \\
\hline Secondary $*$ males & $-0.21(-0.87,0.45)$ & $-0.20(-0.86,0.46)$ & $-0.39(-1.48,-0.09) * *$ \\
\hline More than secondary * males (reference) & - & - & - \\
\hline Average value of & $-0.11(-0.23,-0.01) * *$ & $-0.04(-0.06,-0.02) *$ & $-0.03(-0.04,-0.02) *$ \\
\hline Level 1 variance & $18.45(0.54) * * *$ & $18.63(0.62) * * *$ & $17.69(0.32) * *$ \\
\hline Level 2 variance & $0.59(0.25)^{* *}$ & $0.43(0.38) *$ & $0.22(0.18) *$ \\
\hline Intraclass correlation & $3.1 \%$ & $2,2 \%$ & $1.2 \%$ \\
\hline
\end{tabular}

$95 \% \mathrm{CI}=95 \%$ confidence interval; $\mathrm{P}<0.001 * * * ; \mathrm{P}<0.01 * * ; \mathrm{P}<0.05 *$; CMA $=$ central metropolitan area.

between different types and scales of the "environment" that can and have shaped health negatively or positively, in this case resulting in an increased BMI.

This study provides further evidence on the application of GIS on the development of environmental variables and exploration of the potential association between BMI and the built environment. Using the activity-space-buffers, we were able to demonstrate an association between BMI and the environment, taking into consideration the demographic and socio-economic characteristics of the individuals. For example, elderly populations tend to travel shorter distances and therefore have a shorter buffer size, while younger populations travel more and therefore have a longer buffer size. This finding is particularly important as it demonstrates that relations between the built environment and BMI are sensitive to the mobility patterns of respondents, i.e. the use of buffers based on mobility measures can help uncover a relationship that remained hidden in the case of models based on buffers of arbitrary size (e.g. $1 \mathrm{~km}$ ).

While the relationship between the built environ- 
Table 3. Individual and area-level correlates of BMI based on multi-level modeling analysis - Vancouver, CMA.

\begin{tabular}{|c|c|c|c|}
\hline Variable & $\begin{array}{l}\text { Model } 1 \text { (95\% CI) } \\
\text { (individualised travel-distance) }\end{array}$ & $\begin{array}{l}\text { Model } 2 \text { (95\% CI) } \\
\text { (median distance-traveled) }\end{array}$ & $\begin{array}{l}\text { Model } 3(95 \% \mathrm{CI}) \\
(1 \mathrm{~km} \text { buffer })\end{array}$ \\
\hline Intercept & & $19.51(17.09,21.93) * * *$ & $21.70(21.12,22.27) * * *$ \\
\hline \multicolumn{4}{|l|}{ Age (years) } \\
\hline$<20$ & & $-2.14(-3.14,-1.30) * * *$ & $-2.03(-2.59,-7.14) * * *$ \\
\hline $20-35$ & & $-1.17(-1.51,-0.63) * * *$ & $-0.25(-1.52,-0.57) * *$ \\
\hline 36-50 (reference) & & - & - \\
\hline $51-64$ & & $0.98(0.23,1.77) * *$ & $0.53(0.19,0.87) * *$ \\
\hline$\geq 65$ years of age & & $-1.34(-2.62,-0.54) * *$ & $-0.43(-0.85,0.01)$ \\
\hline Female (reference) & & - & - \\
\hline Male & & $2.73(0.28,3.55) * *$ & $2.52(2.01,3.03) * * *$ \\
\hline Arthritis - rheumatism & & $0.94(0.49,1.39) * * *$ & $0.83(0.50,1.17) * * *$ \\
\hline High blood pressure & & $2.04(1.49,2.45) * * *$ & $1.33(0.97,1.68) * * *$ \\
\hline Diabetes & & $2.07(1.34,2.72) * * *$ & $1.81(1.28,2.35) * * *$ \\
\hline Anxiety - mood disorder & & $0.54(-0.03,1.65)$ & $1.12(0.61,1.62) * * *$ \\
\hline Energy expenditure & & $-0.16(-0.19,-0.05) * * *$ & $-0.10(-3.72,-0.15) * * *$ \\
\hline Regular smoker & & $-0.65(-0.89,-0.21) * * *$ & $-0.67(-4.30,-0.98) * * *$ \\
\hline Race - white & & $2.62(1.94,3.02) * * *$ & $2.51(2.12,12.73) * * *$ \\
\hline Race - Asian (reference) & & - & - \\
\hline Race - other & & $1.68(0.80,2.01) * * *$ & $2.34(1.64,6.56) * * *$ \\
\hline Less than secondary & & $1.18(0.58,1.73) * * *$ & $1.11(0.62,1.60) * * *$ \\
\hline Secondary & & $0.01(-0.04,0.02)$ & $0.47(0.08,2.34) * *$ \\
\hline More than secondary (reference) & & - & - \\
\hline Land use mix & & $-6.24(-7.35,-3.18) * * *$ & $-2.22(-1.28,-0.55) *$ \\
\hline Street connectivity & & $-0.04(-0.01,0.04)$ & $0.002(-1.52,0.001)$ \\
\hline Residential density & & $-0.22(-0.34,-0.02)^{* *}$ & $-0.18(-0.87,-0.03) *$ \\
\hline Anxiety - mood disorder $*$ males & & $-0.64(-0.99,-0.27) *$ & $-1.43(-3.11,-2.34) * *$ \\
\hline Race - white *males & & $0.85(0.23,1.64) * *$ & $-0.45(-1.58,-1.00) *$ \\
\hline Race - Asian * males (reference) & & - & - \\
\hline Race - other $*$ males & & $0.11(-1.17,1.38)$ & $-0.51(-1.55,-0.97)$ \\
\hline Less than secondary $*$ males & & $-1.68(-2.35,-1.11) * *$ & $-1.32(-3.63,-2.03) * *$ \\
\hline Secondary * males & & $-0.20(-0.86,-0.16)^{*}$ & $-0.62(-2.09,-1.20) * *$ \\
\hline More than secondary * males (reference) & & - & - \\
\hline Average value of & & $-0.03(-0.04,-0.02) *$ & $0.02(0.01,0.03) *$ \\
\hline Level 1 variance & & $19.12(0.65) * * *$ & $16.44(0.35) * *$ \\
\hline Level 2 variance & & $0.90(0.48) * *$ & $0.71(0.53) * *$ \\
\hline Intraclass correlation & & $4.5 \%$ & $4.1 \%$ \\
\hline
\end{tabular}

$95 \% \mathrm{CI}=95 \%$ confidence interval; $\mathrm{P}<0.001 * * * \mathrm{P}<0.01 * * ; \mathrm{P}<0.05 * ;$ CMA = central metropolitan area.

ment and obesity has been examined in many studies (Feng et al., 2010; Ding and Gebel, 2012), there is a lack of a clear rationale for choosing built environment measures. For example, while many have used measures of urban form (Ewing et al., 2003; Ross et al., 2007), others have explored the potential association between weight status and the built environment using measures of walkability and accessibility (Frank et al., 2004; Powell et al., 2007). Nevertheless, few studies have undertaken similar approaches to explore the association between weight status and the built environment using measures of land use, residential density, street network connectivity and measures of accessibility (e.g. density of fast-food restaurants). Findings from this study indicate though, that compared to accessibility, measures of land use and residential density were generally better indicators of the built environment for both Toronto and Vancouver. This is useful since employing a more sensitive estimate of the built environment could be used to better assess the environmental determinants of increased BMI. 
Table 4. Variance inflation factor for the built environment variables for Toronto and Vancouver.

\begin{tabular}{|c|c|c|c|c|c|}
\hline \multicolumn{6}{|l|}{ Toronto } \\
\hline Variable & Parameter estimate & Standard error & $\mathrm{t}$ value & $\operatorname{Pr}>|t|$ & Variance inflation \\
\hline \multicolumn{6}{|c|}{$1 \mathrm{~km}$} \\
\hline Intercept & 25.22 & 0.14 & 18.69 & $<0.001$ & 0.00 \\
\hline Landuse & -0.16 & 0.24 & -0.67 & 0.50 & 1.00 \\
\hline Residential & -0.08 & 0.03 & -3.03 & $<0.001$ & 1.01 \\
\hline Street & -0.001 & 0.001 & -2.09 & 0.04 & 1.01 \\
\hline \multicolumn{6}{|c|}{ Median distance-traveled buffer } \\
\hline Intercept & 20.72 & 1.14 & 18.14 & $<0.001$ & 0.00 \\
\hline Landuse & -5.72 & 1.53 & 3.74 & $<0.001$ & 1.16 \\
\hline Residential & -0.001 & 0.002 & -0.80 & 0.04 & 1.09 \\
\hline Street & -0.007 & 0.003 & -2.22 & 0.03 & 1.11 \\
\hline \multicolumn{6}{|c|}{ Distance-traveled } \\
\hline Intercept & 20.91 & 1.15 & 18.17 & $<0.001$ & 0.00 \\
\hline Landuse & -5.72 & 1.53 & 3.74 & $<0.001$ & 1.00 \\
\hline Residential & -0.07 & 0.03 & -2.09 & 0.04 & 1.01 \\
\hline Street & -0.001 & 0.002 & -0.73 & 0.47 & 1.01 \\
\hline \multicolumn{6}{|l|}{ Vancouver } \\
\hline Variable & Parameter estimate & Standard error & $\mathrm{t}$ value & $\operatorname{Pr}>|t|$ & Variance inflation \\
\hline \multicolumn{6}{|c|}{$1 \mathrm{~km}$} \\
\hline Intercept & 25.45 & 0.19 & 135.94 & $<0.001$ & 0.00 \\
\hline Landuse & -2.75 & 0.36 & -2.08 & 0.04 & 1.31 \\
\hline Residential & 0.24 & 0.18 & 0.13 & $<0.001$ & 1.27 \\
\hline Street & -0.004 & 0.001 & -3.08 & $<0.001$ & 1.18 \\
\hline \multicolumn{6}{|c|}{ Median distance-traveled } \\
\hline Intercept & 24.64 & 0.06 & 402.69 & $<0.001$ & 0.00 \\
\hline Landuse & -4.04 & 1.30 & 3.11 & $<0.001$ & 1.06 \\
\hline Residential & -0.30 & 0.16 & -1.92 & 0.03 & 1.07 \\
\hline Street & -0.01 & 0.001 & -4.15 & $<0.001$ & 1.19 \\
\hline
\end{tabular}

Average dwelling value was related to BMI independently of individual-level characteristics. There is a growing understanding that average dwelling value is an expression of individual-level socio-economic status (Dunn, 2002) and that aggregate measures of average dwelling values may be sensitive measures of neighbourhood socio-economic position (Cozier et al., 2007).

The social environment indicators (i.e. member of a voluntary organisation and sense of belonging in the local community) were not significantly associated with BMI. This may be due to the following: the variables used are not adequate measures of the social environment; or more simply, that the social environment does not equate with the weight status of individuals in urban Canada. However, the last explanation seems unlikely given that studies have found that social envi- ronment indicators are significantly associated with weight status (Cohen et al., 2006; King et al., 2006).

In general, our findings are consistent with existing literature on gender differences with respect to weight and this study underlines that the use of interaction terms could demonstrate potential differences on the determinants of overweight/obesity between the two genders. Indeed, the gender differences on the determinants of overweight/obesity could potentially be due to differences in the social constructs of gender (Diamond, 2000). For example, research findings from related studies have suggested that overweight and obese females are more likely to be diagnosed with a psychosocial disorder (e.g. anxiety, mood disorder) than males (Steptoe et al., 2000). Gender differences on the relationship between educational attainment and BMI could result from a number of mediat- 
ing factors such as social perceptions/norms and availability of resources (Crosnoe, 2007).

Possible limitations include the fact that the study is based on a cross-sectional design. However, the relationships uncovered are well established in the literature, and the direction of the relationships is sensible. Further, the BMI data used were based on self-reported information. Still, given that individuals tend to over-report their height and under-report their weight (Katzmarzyk, 2002), the associations reported here should be considered conservative. Third, determining the optimal buffer size for measuring environmental characteristics needs further consideration. While we present results using a $1 \mathrm{~km}$, activity-space-buffers and median travel-distance-based buffers, further research is needed. Although the results here indicate that a buffer based on distance travelled is a vast improvement over previous estimates, we were only able to use the available model for Toronto. Fourth, although additional built environment correlates such as sidewalks, trees, traffic speed and volume as well as intersection design have been found to be correlated to increased BMI (Frank and Engelke, 2001; Frank et al., 2004), only variables available in the DMTI database could be examined and included in the present study. Further studies are thus needed to evaluate associations between BMI and a greater range of built environment variables. Yet, the variations in the BMI established in this study verify the contribution of the individual and area-level factors on increased BMI in urban Canada. Finally, we should also acknowledge that variables relating to aspects of health status (notably blood pressure and diabetes) are equally likely to be outcomes of BMI as well as determinants. We therefore included such variables only as controls for our models, i.e. we do not suggest that high blood pressure causes overweight/obesity. Rather, the role of control variables such as health (blood pressure, diabetes), ethnicity, smoking, age and gender is to reveal the true effects of the determinants of overweight/obesity such as physical activity, built environment and level of education independently of the impact of blood pressure and diabetes.

\section{Conclusions}

The findings established in this study underscore the results of previous studies by confirming that individual, socio-economic and environmental characteristics both at the individual and area level of analysis play a significant role in explaining the variation of BMI. In addition, the incorporation of built environment meas- ures demonstrate the effectiveness of GIS applications and offer new evidence with regard to the relative contribution of the built environment. Employing different measures of the built environment could therefore modify their potential association with increased BMI.

Although the overwhelming amount of variation in BMI occurred at the individual level, we found incremental effects at the area-level of analysis as well. That is, this study added to growing evidence suggesting that targeting high-risk individuals will only address a portion of the overweight/obesity problem, and that it is also important to address the places that compel individuals to make unhealthy choices.

\section{References}

Berrigan D, Troiano RP, 2002. The association between urban form and physical activity in U.S. adults. Am J Prev Med 23, 74-79.

Boer R, Zheng Y, Overton A, Ridgeway GK, Cohen DA, 2007. Neighborhood design and walking trips in ten U.S. metropolitan areas. Am J Prev Med 32, 298-304.

Brown B, Perkins D, Brown G, 2003. Place attachment in a revitalizing neighbourhood: individual and block levels of analysis. J Environ Psychol 23, 259-271.

Chaix B, Merlo J, Evans D, Leal C, Havard S, 2009. Neighbourhoods in eco-epidemiologic research: delimiting personal exposure areas. A response to Riva, Gauvin, Apparicio and Brodeur. Soc Sci Med 69, 1306-1310.

Cohen DA, Finch BK, Bower A, Sastry N, 2006. Collective efficacy and obesity: the potential influence of social factors on health. Soc Sci Med 62, 769-778.

Cozier YC, Palmer JR, Horton NJ, Fredman L, Wise LA, Rosenberg L, 2007. Relation between neighbourhood median housing value and hypertension risk among black women in the United States. Am J Public Health, 97, 718-723.

Crosnoe R, 2007. Gender, obesity, and education. Soc Educ 80, 241-260.

Diamond M, 2000. Sex and gender: same or different? Fem Psychol 10, 46-54.

Ding D, Gebel K, 2012. Built environment, physical activity, and obesity: what have we learned from reviewing the literature? Health Place 18, 100-105.

Dunn JR, 2002. Housing and inequalities in health: a study of socioeconomic dimensions of housing and self-reported health from a survey of Vancouver residents. J Epidemiol Community Health 56, 671-681.

ESRI, 2002. ArcView GIS 3.3. Redlands: ESRI.

Evans RG, Barer ML, Marmor TR , 1994. Why are some people healthy and others not? The determinants of health of populations. New York: Ardine de Gruyter.

Ewing R, Schmid T, Killingsworth R, Zlot A, 2003. 
Relationship between urban sprawl, physical activity, obesity and morbidity. Am J Health Promot 18, 47-57.

Feng J, Glass TA, Curriero FC, Stewart WF, Schwartz BS, 2010. The built environment and obesity: a systematic review of the epidemiologic evidence. Health Place 16, 175-190.

Frank L, Engelke P, 2001. The built environment and human activity patterns: exploring the impacts of urban form on public health. J Plan Lit 16, 202-218.

Frank L, Kerr J, Saelens B, Sallis J, Glanz K, Chapman J, 2009. Food outlet visits, physical activity and body weight: variations by gender and race-ethnicity. Br J Sports Med 43, 124131.

Frank L, Sallis J, Conway T, Chapman J, Saelens B, Bachman W, 2006. Many pathways from land use to health. JAPA 72, 75-87.

Frank LD, Andresen MA, Schmid TL, 2004. Obesity relationships with community design, physical activity, and time spent in cars. Am J Prev Med 27, 87-96.

Frank LD, Kerr J, Sallis JF, Miles R, Chapman J, 2008. A hierarchy of sociodemographic and environmental correlates of walking and obesity. Prev Med 47, 172-178.

Harrington D, Elliott S, 2009. Weighing the importance of neighbourhood: a multilevel exploration of the determinants of overweight and obesity. Soc Sci Med 68, 593-600.

Herrera B, Lindgren C, 2010. The genetics of obesity. Curr Diabetes Rep 10, 498-505.

Janssen I, 2013. The public health burden of obesity in Canada. Can J Diabetes 37, 90-96.

Katzmarzyk PT, 2002. The Canadian obesity epidemic: an historical perspective. Obes Res 10, 666-674.

King T, Kavanagh A, Jolley D, Turrell G, Crawford D, 2006. Weight and place: a multilevel cross-sectional survey of arealevel social disadvantage and overweight/obesity in Australia. Int J Obes 30, 281-287.

Kwan MP, 1999. Gender and individual access to urban opportunities: a study using space-time measures. Prof Geogr 51, 210-227.

Lahti-Koski M, Vartiainen E, Mannisto S, Pietinen P, 2000. Age, education and occupation as determinants of trends in body mass index in Finland from 1982 to 1997 . Int J Obes Relat Metab Disord 24, 1669-1676.

Leslie E, Coffee N, Frank L, Owen N, Bauman A, Hugo G, 2007. Walkability of local communities: using geographic information systems to objectively assess relevant environmental attributes. Health Place 13, 111-122.

Mobley LR, Finkelstein EA, Khavjou OA, Will JC, 2004. Spatial analysis of body mass index and smoking behaviour among WISEWOMAN participants. J Womens Health 13, 519-528.

Morency C, Paez A, Roorda MJ, Mercado R, Farber S, 2011. Distance traveled in three Canadian cities: spatial analysis from the perspective of vulnerable population segments. J Trans Geogr 19, 39-50.

Navalpotro L, Regidor E, Ortega P, Martínez D, Villanueva R,
Astasio P, 2012. Area-based socioeconomic environment, obesity risk behaviours, area facilities and childhood overweight and obesity: socioeconomic environment and childhood overweight. Prev Med 55, 102-107.

Nelson MC, Gordon-Larsen P, Song Y, Popkin BM,2006. Built and social environments: associations with adolescent overweight and activity. Am J Prev Med 31, 109-117.

Páez A, Gertes Mercado R, Farber S, Morency C, Roorda M, 2010. Relative accessibility deprivation indicators for urban settings: definitions and application to food deserts in Montreal. Urban Stud 47, 1415-1438.

Poortinga W, Gebel K, Bauman A, Moudon AV, 2011. Neighborhood environment, physical activity and obesity. In: Encyclopedia of Environmental Health. Nriagu JO (ed), Burlington: Elsevier, 44-53 pp.

Powell LM, Auld C, Chaloupka FJ, O’Malley PM, Johnston LD, 2007. Associations between access to food stores and adolescent body mass index. Am J Prev Med 33, S301-S307.

Public Health Agency of Canada \& Canadian Institute for Health Information, 2011. Obesity in Canada: a joint report from the Public Health Agency of Canada and the Canadian Institute for Health Information.

Raine KD, 2004. Overweight and obesity in Canada: a population health perspective. Ottawa, ON, Canada: Canadian Population Health Initiative and Canadian Institute for Health Information.

Rasbash J, Charlton C, Browne WJ, Healy M, Cameron B, 2009. MLwiN Version 2.1. Centre for Multilevel Modelling. Bristol: University of Bristol.

Robert SA, Reither EN, 2004. A multilevel analysis of race, community disadvantage, and body mass index among adults in the US. Soc Sci Med 59, 2421-2434.

Ross NA, Tremblay S, Khan S, Crouse D, Tremblay D, Berthelot J, 2007. Body Mass Index in urban Canada: neighbourhood and metropolitan area effects. Am J Public Health 97, 500508.

SAS Institute Inc., 2008. SAS/STAT® 9.2 User's Guide. Cary, NC. Snijders T, Bosker R, 1999. Multilevel analysis: an introduction to basic and advanced multilevel modeling. London: Sage Publication.

Statistics Canada, 2005a. Canadian Community Health Survey (CCHS), Cycle 3.1. Ottawa, ON: Health Statistics Division.

Statistics Canada, 2005b. Health regions: boundaries and correspondence with census geography. Ottawa, ON: Health Statistics Division.

Statistics Canada, 2008. 2006 Census Dictionary. Statistics Canada Catalogue no. 92-566-XWE. Ottawa, Ontario.

Steptoe A, Rink E, Kerry S, 2000. Psychosocial predictors of changes in physical activity in overweight sedentary adults following counselling in primary care. Prev Med 31, 183-194.

Swinburn B, Egger G, Raza F, 1999. Dissecting obesogenic environments: the development and application of a framework 
for identifying and prioritizing environmental interventions for obesity. Prev Med 29, 563-570.

Tjepkema M, 2005. Measured obesity: adult obesity in Canada: measured height and weight. Nutrition: findings from the Canadian Community Health Survey. Ottawa, ON: Statistics Canada.
WHO, 2013. Obesity and overweight. Geneva: World Health Organization.

Zick CD, Smith KR, Fan JX, Brown BB, Yamada I, KowaleskiJones L, 2009. Running to the store? The relationship between neighborhood environments and the risk of obesity. Soc Sci Med 69, 1493-1500. 